\title{
Orthostatic Hypotension among the Elderly Hypertensives in Anambra State, South Eastern Nigeria
}

Enwonwu $\mathrm{KG}^{1}$, Ibeh $\mathrm{C}^{1}$, Modebe $\mathrm{I}^{1}$, Owoaje $\mathrm{E}^{2}$, Zoakah $\mathrm{AI}^{3}$, Ifeadike $\mathrm{C}^{1}$, Ezeama $\mathrm{N}^{1}$, Azuike $\mathrm{E}^{1}$. ${ }^{1}$ Department of Community Medicine, Nnamdi Azikiwe University Teaching Hospital, Nnewi, Anambra State, Nigeria

${ }^{2}$ School of Public Health, University College Hospital Ibadan, Nigeria

${ }^{3}$ Department of Community Medicine, University of Jos, Nigeria

Correspondence: Enwonwu KG: Email - keneokocha@ymail.com. Phone - 08034533900

\begin{abstract}
Background: Orthostatic hypotension is a sustained reduction of systolic blood pressure of at least $20 \mathrm{mmHg}$ or diastolic blood pressure of at least $10 \mathrm{mmHg}$ within three minutes of standing from supine position. The burden of orthostatic hypotension on public health is substantial, with a prevalence of $7 \%$ to $55 \%$ in the elderly and is higher in those with risk factors especially hypertension, use of antihypertensive drugs and diabetes mellitus. The objective of this study was to determine the prevalence of orthostatic hypertension among the elderly hypertensives in Anambra State.
\end{abstract}

Methods: This was a community based cross-sectional study among 400 elderly people aged 60 years and above who were recruited using a multistage sampling method. Data was collected using interviewer administered questionnaire. Mercury sphygmomanometer, weighing scale, stadiometer and glucometer were used to record blood pressure, body weight, height and random blood sugar respectively. Statistical analysis was done using Statistical Package for the Social Sciences version 21 and p value $\leq 0.05$ was considered statistically significant.

Results: Most of the participants had either systolic or diastolic hypertension $(85.8 \%)$. The prevalence of orthostatic hypotension was $14.8 \%$ in the study population and $16.3 \%$ among those who were hypertensive. Those with supine diastolic hypertension [OR: 1.699 (95\% CI: 0.401-7.209)] were more likely than those without supine diastolic hypertension to have orthostatic hypotension.

Conclusion: The prevalence of orthostatic hypotension among elderly hypertensives aged 60 years and above in Anambra State was found to be relatively high, implying a higher risk of orthostatic hypotension in elderly hypertensives than in normotensives. This finding will aid clinicians in better management of elderly patients which will lead to prevention of the various complications due orthostatic hypotension.

Keywords: blood pressure, orthostatic hypotension, elderly, hypertensive

\section{Introduction}

Orthostatic hypotension $(\mathrm{OH})$ is a common condition in the elderly with substantial public health burden and is associated with significant risk of morbidity and mortality. Studies have shown that hypertension is a 
risk factor for $\mathrm{OH}^{1,2}$ The mechanism of $\mathrm{OH}$ in hypertensives is related to impaired baroreflex sensitivity due to a decrease in vascular compliance and consequent diminution of baroreceptor stretch and relaxation during blood pressure (BP) change. ${ }^{3-5}$ Hypertension and many antihypertensive medications can exacerbate age-related impairments of the physiological processes that regulate blood flow after orthostasis, causing $\mathrm{OH}^{6}{ }^{6}$ Supine hypertension means high blood pressure in the supine position when blood pressure is normal when seated or standing and it is defined as a systolic blood pressure of $\geq 140 \mathrm{~mm} \mathrm{Hg}$ and diastolic blood pressure of $\geq 90 \mathrm{~mm} \mathrm{Hg}$ while lying down. ${ }^{7}$ It may be symptomless or may present with non-specific symptoms such as light headedness, blurring of vision and weakness which may lead to decreased functional capacity, and can be easily overlooked during evaluation of older patients. $^{8}$ The essential clinical dilemma that these patients pose for clinicians is how to provide a degree of protection against future adverse vascular events, particularly stroke, while not predisposing them to syncope and falls and therefore fractures due to $\mathrm{OH}$. The combination of hypertension with $\mathrm{OH}$ appears to be common, with studies reporting a high prevalence of $\mathrm{OH}$ in hypertensives. ${ }^{3,8}$

A study done in Boston to investigate the relationships between uncontrolled and controlled hypertension with $\mathrm{OH}$ reported a higher prevalence of $\mathrm{OH}$ among uncontrolled hypertensives than their counterparts with controlled hypertension and also a higher prevalence in those with hypertension than in those without hypertension. ${ }^{9}$ This study's findings are in keeping with those from studies done in Sweden and Alabama. ${ }^{10,11}$ Other studies done in different parts of the world have also shown that reducing or normalizing blood pressure by treatment for hypertension in elderly hypertensives decreases the prevalence and burden of $\mathrm{OH} .{ }^{12-23}$ The prevalence of $\mathrm{OH}$ among hypertensives is also higher relative to normotensives in Africa as shown by the study done in Mali on hypertensives aged 15 years and above, which found a prevalence of $31.8 \%{ }^{24}$ There are no known studies in Nigeria on the prevalence of $\mathrm{OH}$ in elderly hypertensives . Findings from this study will aid clinicians in better management of elderly patients with hypertension. This will in turn prevent complications from this condition and improve their daily functional activities and quality of life. The resulting increased self-dependence of those affected will reduce their psychological and socioeconomic burden on their relatives and care givers.

\section{Methods}

The study was part of a community based cross-sectional study conducted among the elderly in Anambra State, south eastern region of Nigeria. Sample size was determined using the formula for sample size determination in a finite population ( $p$ $=$ prevalence of orthostatic hypotension in community dwelling elderly in Finland $34 \%){ }^{13,25}$ A multistage sampling method was used to select consenting elderly people aged 60 years and above. Anambra State has three senatorial zones and 21 Local Government Areas (LGAs). Two senatorial zones- Anambra North and Anambra Central were selected using simple random sampling method (balloting method).

Two LGAs were selected from each senatorial zone - Anambra East and Oyi LGAs from Anambra North senatorial zone, and Anaocha and Dunukofia LGAs from Anambra Central senatorial zone using simple random sampling method 
(balloting method). This gave a total of four LGAs. Two towns were selected from each LGA using simple random sampling method (balloting method). This gave a total of eight towns - Aguleri and Umueri from Anambra East LGA, Nkwelle Ezunaka and Ogbunike from Oyi LGA, Neni and Adazi-ani from Anaocha LGA, Ukpo and Ifitedunu from Dunukofia LGA. All consenting elderly people aged 60 years and above in the selected communities were enrolled while those among them who could not stand up on their own (standing blood pressure needed to be measured) and those with visual or hearing defects (due to associated balance impairment) were excluded from the study.

Data was collected using an interviewer administered questionnaire which was validated using Cronbach's alpha with a coefficient of reliability of 0.73 . Blood Pressure was measured with a mercury sphygmomanometer following the standardized protocol by The Seventh Report of the Joint National Committee on Prevention, Detection, Evaluation and Treatment of High Blood Pressure. ${ }^{26}$ Supine measurements were taken after at least 5 minutes of rest in the supine position on the health centre's examination couch. For standing BP, two measurements were taken, one at 0 minute and the other at 2 minutes after standing from supine position. Blood Pressures measured at 0 minutes was taken at the moment after rising from the supine to standing positions (usually within 15 seconds from the last supine measurement). Hypertension was defined as an average of two BP measurements $\geq 140$ (systolic) or $\geq 90$ (diastolic) $\mathrm{mm} \mathrm{Hg}$, positive response to hypertension question and current use of an antihypertensive medication on the medical history questionnaire.
Data analysis was done using Statistical Package for the Social Sciences (SPSS) software version 21 . The mean ages of the participants with and without $\mathrm{OH}$ were compared using one sample t-test for any significant difference. The means of the supine and standing systolic and diastolic blood pressures of participants with and without $\mathrm{OH}$ were also compared using the one sample t-test. A p value of $\leq 0.05$ was considered statistically significant.

Ethical approval was obtained from the NnamdiAzikiwe University Teaching Hospital Ethics Committee (NAUTHEC). A written informed consent was obtained from each of the participants after a detailed explanation of the procedures involved. Those that could not read or write, thumb printed. Confidentiality was assured by not using names and participation was voluntary. Withdrawal could be verbal. Permission to conduct the study was obtained from traditional rulers and the officials of the town unions.

\section{Results}

There were more females; 209 (52.3\%) than males; 191(47.7\%) in the study population. The study population had a mean age of $70.62 \pm 7.97$ years. The age group 60 to 64 years were the most; $99(24.7 \%)$ and they were mostly active farmer/artisans; $132(33.0 \%)$. (Table 1). Table 2 shows that a large number of the participants were hypertensive; 343 $(85.8 \%)$ and 56(16.3\%) among those with hypertension had $\mathrm{OH}$. There was a statistically significant relationship between systemic hypertension and orthostatic hypotension $(\mathrm{p}=0.027)$. The prevalence of $\mathrm{OH}$ among hypertensives was $16.3 \%$ and among normotensives $5.3 \%$.

There were statistically significant differences in the mean supine systolic BP 
between those with $\mathrm{OH}$ and those without $\mathrm{OH}(\mathrm{p}<0.001)$ and in the mean supine diastolic BP between those with $\mathrm{OH}$ and those without $\mathrm{OH}(\mathrm{p}<0.001)$. However, there were no statistically significant differences in the mean standing systolic BP between those with $\mathrm{OH}$ and those without $\mathrm{OH}(\mathrm{p}=0.269)$ and in the mean standing diastolic BP between those with $\mathrm{OH}$ and those without $\mathrm{OH}(\mathrm{p}=0.089$, Table 3). Those with supine diastolic hypertension were about 2 times more likely to have $\mathrm{OH}$ than those without supine diastolic hypertension (OR: 1.699, CI: 0.401-7.209, $\mathrm{p}=0.000)$. Table 4

Table 1 Demographic characteristics of the study population

\begin{tabular}{lcc}
\hline Characteristics & Frequency & Percentage (\%) \\
\hline Sex & 191 & \\
Male & 209 & 47.7 \\
Female & 400 & 52.3 \\
Total & & 100.0 \\
Age (years) & 99 & \\
$60-64$ & 82 & 24.7 \\
$65-69$ & 89 & 20.5 \\
$70-74$ & 62 & 22.3 \\
$75-79$ & 68 & 15.5 \\
$80+$ & 400 & 17.0 \\
Total & & 100.0 \\
Mean(SD) $70.62(7.97)$ & & \\
Occupation & 79 & 19.7 \\
Active trader & 55 & 13.8 \\
Retired trader & 2 & 0.5 \\
Active civil servant & 35 & 8.8 \\
Retired civil servant & 132 & 33.0 \\
Active farmer/artisan & 97 & 24.2 \\
Retired farmer/artisan & 400 & 100.0 \\
Total & &
\end{tabular}

Table 2 Relationship between orthostatic hypotension and systemic hypertension

\begin{tabular}{lrrrrr}
\hline Variables & \multicolumn{1}{c}{ OH } & NOH & Total & $\chi^{2}$ & P-value \\
\hline Systemic BP & & & & & \\
Hypertensive & $56(16.3)$ & $287(83.7)$ & 343 & 4.758 & $0.027^{*}$ \\
Normotensive & $3(5.3)$ & $54(94.5)$ & 57 & & \\
Total & 59 & 341 & 400 & & \\
\hline
\end{tabular}

$\mathrm{OH}:$ Orthostatic hypotension

NOH: No orthostatic hypotension 
Table 3 Relationship between $\mathrm{OH}$ and supine and standing BP of participants

\begin{tabular}{lrrrc}
\hline Variables & \multicolumn{1}{c}{ OH } & NOH & T-test(one sample) & P-value \\
\hline BP & & & & \\
MSUS (SD) & $159.4(23.2)$ & $146.9(16.8)$ & 3.945 & $<0.001^{*}$ \\
MSUD (SD) & $91.5(11.0)$ & $87.3(7.4)$ & 2.832 & $<0.001^{*}$ \\
MSTS (SD) & $148.7(18.0)$ & $145.9(17.5)$ & 1.106 & 0.269 \\
MSTD (SD) & $86.1(9.7)$ & $88.0(7.6)$ & -1.703 & 0.089 \\
\hline
\end{tabular}

* Statistically Significant

MSUS - Mean supine systolic, MSUD - Mean supine diastolic, MSTS - Mean standing systolic, MSTD - Mean standing diastolic, SD - Standard deviation.

Table 4: Relationship between supine systolic hypertension and supine diastolic hypertension, and $\mathrm{OH}$ among respondents

\begin{tabular}{lrrrrr}
\hline Variables & \multicolumn{1}{c}{ OH } & \multicolumn{1}{c}{ NOH } & OR & 95\% CI & P-value \\
\hline Hypertensives & $56(94.9)$ & $287(84.2)$ & 0.801 & $0.406-13.984$ & 0.027 \\
Normotensives & $3(5.1)$ & $54(15.8)$ & 1 & & \\
SSTHT & $54(91.5)$ & $242(71.0)$ & 0.931 & $0.084-10.327$ & 0.001 \\
No SSTHT & $2(8.5)$ & $45(29.0)$ & 1 & & \\
SDTHT & $48(81.3)$ & $125(36.6)$ & 1.699 & $0.401-7.209$ & $<0.001$ \\
No SDTHT & $8(18.7)$ & $162(63.4)$ & 1 & & \\
MSUS (SD) & $159.4(23.2)$ & $146.9(16.8)$ & 0.776 & $0.709-0.849$ & $<0.001$ \\
MSUD (SD) & $91.5(11.0)$ & $87.3(7.4)$ & 0.567 & $0.472-0.681$ & $<0.001$ \\
\hline
\end{tabular}

SSTHT - supine systolic hypertension, SDTHT - supine diastolic hypertension MSUS - mean supine systolic BP, MSUD - mean supine diastolic BP.

\section{Discussion}

Orthostatic hypotension is described as a common disorder in the elderly, particularly in the acute medical setting. The results revealed that among those found to have $\mathrm{OH}$, a large majority had both supine systolic hypertension and supine diastolic hypertension while those with supine diastolic hypertension were about 2 times more likely to have $\mathrm{OH}$ compared to those without it. This shows that having supine hypertension is a risk factor for $\mathrm{OH}$ while supine diastolic hypertension is an independent risk factor for $\mathrm{OH}$. These findings are consistent with reports in other studies. ${ }^{3,8,9,10,15,27}$ Most of the studied elderly persons were hypertensive and 1 in every 6 of these hypertensives had orthostatic hypotension. There was a statistically significant relationship between hypertension and $\mathrm{OH}$ but overall hypertension was not found to be an independent risk factor for orthostatic hypotension.

Hypertension is among the most common comorbidities associated with $\mathrm{OH}$ and its presence complicates the management of these patients because treatment of one can worsen the other. However, there is evidence that uncontrolled hypertension worsens $\mathrm{OH}$ so that both should be managed. ${ }^{28}$ Patients with isolated supine hypertension can be treated with bedtime doses of short-acting antihypertensives. ${ }^{29}$ 
Treatment of $\mathrm{OH}$ in the hypertensive patients should focus foremost on the removal of drugs that can worsen $\mathrm{OH}^{29}$ Oral water bolus acutely but transiently increases blood pressure in autonomic failure patients. Management of $\mathrm{OH}$ in the hypertensive patient is challenging but a management strategy based on understanding the underlying pathophysiology can be effective in most patients.

In terms of study limitation, the prevalence of orthostatic hypotension is higher in the sick and frail who were excluded from this study because of inability to stand on their own. This had the potential of underestimating the prevalence of $\mathrm{OH}$. In addition, blood pressure was taken only once during the day and literature indicates that $\mathrm{OH}$ varies over the course of the day.

\section{Conclusion}

The prevalence of orthostatic hypotension among elderly hypertensives aged 60 years and above in Anambra State was found to be high. Supine systolic hypertension and supine diastolic hypertension were significantly associated with $\mathrm{OH}$ while the presence of supine diastolic hypertension was an independent risk factor of $\mathrm{OH}$. Elderly persons with hypertension should receive regular monitoring of supine and upright blood pressure in order to detect $\mathrm{OH}$ and prevent its complications.

\section{References}

1. Kearney F, Moore A. Treatment of combined hypertension and orthostatic hypotension in older adults: more questions than answers still remain. Expert Rev Cardiovasc Ther.2009;7(6): 557560.
2. Jordan J, Biaggioni I. Diagnosis and Treatment of Supine Hypertension in Autonomic Failure Patients with Orthostatic Hypotension. The Journal of Clinical Hypertension 2002;4: 139145.

3. Naschitz JE, Slobodin G, Elias N, Rosner I. The patient with supine hypertension and orthostatic hypotension: a clinical dilemma.Postgrad Med J. 2006;82(966): 246-253.

4. Goldstein DS, PechnikS, Holmes C, Eldadah B. Association Between Supine Hypertension and Orthostatic Hypotension in Autonomic Failure.

Hypertension.2003; 42: 136-142.

5. Lee T, Donegan C, Moore A.

Treatment of combined hypertension and orthostatic hypotension in older patients: a treatment dilemma for clinicians. Expert Rev. Cardiovasc. Ther. 2005; 3(3): 443-440.

6. Shin C, Abbott RD, Lee H, Kim J, Kimm K. Prevalence and correlates of orthostatic hypotension in middle-aged men and women in Korea: the Korean Health and Genome Study. J Hum Hypertens. 2004;18: 717-723.

7. Medow MS, Stewart JM, Sanyal S, Mumtaz A, William DS, Frishman H. Pathophysiology, Diagnosis and Treatment of Orthostatic Hypotension and Vasovagal Syncope. Cardiology in Review 2008; 16(1):4-20.

8. Hosokawa K, Ide T, Tobushi T, Sakamoto K, Onitsuka K. Bionic Baroreceptor Corrects Postural Hypotension in Rats With Impaired Baroreceptor. Circulation. 2012; 126:1278-1285. 
9. Gangavati A, Hajjar I, Quach L, Jones RN, Kiely DK, Gagnon P et al. Hypertension, orthostatic hypotension and the risk of falls in a community-dwelling elderly population: the maintenance of balance, independent living, intellect, and zest in the elderly of Boston study. J Am Geriatr Soc. 2011;59(3):383-389.

10. Fedorowski, Burri P. Melander O. Orthostatic hypotension in genetically related hypertensive and normotensive individuals. J Hypertens. 2009 ;27(5):976-82.

11. Judd E, Calhoun DA. Hypertension and orthostatic hypotension in older patients. J Hypertens (Los Angel). 2012;30(1):38-39.

12. Saez T, Suarez C, Sierra MJ. Orthostatic hypotension in the aged and its association with antihypertensive treatment. Med Clin (Barc) .2000;11(45) :525-529.

13. Hiitola P, Enlund H, Kettunen R, Sulkava R, Hartikainen S. Postural changes in blood pressure and the prevalence of orthostatic hypotension among home-dwelling elderly aged 75 years or older. J Hum Hypertens. 2009;23:33-39

14. Kartheek BR, Kumar G, Begum SA, Venkateswaraiah S. Postural changes in blood pressure associated with ageing. International Journal of Life Science and Pharma Research 2011; 1(1):88-93.

15. Kamaruzzaman S, Watt H, Carson C, Ebrahim S. The association between orthostatic hypotension and medication use in the British Women's Heart and Health Study. Ageing 2010; 39: 51-56.

16. Masuo K, Mikami H, Ogihara T, Tuck ML. Changes in frequency of orthostatic hypotension in elderly hypertensive patients under medications. Am J Hypertens. 1996; 9:263-268.

17. Milazzo V, Di Stefano C,Servo S, Crudo V, FulcheriC,Maule S. Drugs and Orthostatic Hypotension: Evidence from Literature.Journal of Hypertension.2012; 1:104-112.

18. Rose KM, Eigenbrodt ML, Biga RL, Couper DJ, Light KC.

Orthostatic hypotension predicts mortality in middle-aged adults: the Atherosclerosis Risk In Communities (ARIC) Study. Circulation 2006; 114:630-636.

19. Van Buren PN, Adams-Huet B, Toto RD. Effective antihypertensive strategies for highrisk patients with diabetic nephropathy. J Investig Med. 2010;58: 950-956.

20. Weir MR, Neutel JM, Bhaumik A, De Obaldia ME, Lapuerta P. The efficacy and safety of initial use of irbesartan/hydrochlorothiazide fixed-dose combination in hypertensive patients with and without high cardiovascular risk. J ClinHypertens (Greenwich) .2007;9: 23-30.

21. Raiha I, Luutonen S, Piha J, Seppanen A, Toikka T. Prevalence, predisposing factors, and postural hypotension. Arch Intern Med. 1995; 155:930-935.

22. Ha AD, Borwn $\mathrm{CH}$, York MK, Jankovic J. The prevalence of symptomatic orthostatic hypotension in patients with Parkinson's disease and atypical parkinsonism. Parkinsonism Relat Disord.2011; 17:625-628.

23. Musso G, Alfie J. Resistant Hypertension in the Elderly-Second Line Treatments: Aldosterone Antagonists, Central Alpha-Agonist Agents, Alpha-Adrenergic Receptor 
Blockers, Direct Vasodilators, and Exogenous Nitric Oxide Donors. Cardiovascular and Haematological Agents in Medicinal Chemistry 2014; 12(4): 170-173.

24. Oumar B, Ichaka M, Ibrahima S, Noumou S, Bella DI, Souleymane $\mathrm{C}$ et al. Orthostatic Hypotension in a Population of Hypertensive Patients in the University Hospital Gabriel Touré. Clinical Medicine Research 2015; 4( 4) : 116-119

25. Araoye MO. Research Methodology with Statistics for Health and Social Sciences: Sample size determination. Nathadex publishers. Nigeria .2004. p. 115120.

26. Chobanian AV, Bakris GL, Black HR, Cushman WC, Green LA, IzzoJr JL et al . The Seventh Report of the Joint National
Committee on Prevention, Detection, Evaluation, and Treatment of High Blood Pressure. JAMA. 2003;289(19):2560-2571

27. Wu J, Yang Y, Lu F, Wu C, Chang C. Population-based study on the prevalence and correlates of orthostatic hypotension/hypertension and orthostatic dizziness. Hypertens Res. 2008; 31(5): 897-904.

28. Enrique AL, Andrea AC, Angeles C, Karla LC, Pablo ED. Prevalence of orthostatic hypotension in a series of elderly Mexican institutionalized patients. Cardiol J. 2011;18(3): 282-288

29. Masuo K, Mikami H, Ogihara T, Tuck ML. Changes in frequency of orthostatic hypotension in elderly hypertensive patients under medications. Am J Hypertens. 